\title{
РОЛЬ НАЦИОНАЛЬНЫХ ВАЛЮТ ГОСУДАРСТВ-ЧЛЕНОВ ЕАЭС В МЕЖДУНАРОДНЫХ РАСЧЁТАХ: ФАКТОРЫ СДЕРЖИВАНИЯ И НАПРАВЛЕНИЯ ПОВЫШЕНИЯ "
}

\author{
(c) 2021 Пищик Виктор Яковлевич \\ доктор экономических наук, профессор Департамента мировых финансов \\ Финансовый университет при Правительстве Российской Федерации, Россия, Москва \\ E-mail:vpiwik@fa.ru \\ (c) 2021 Алексеев Петр Викторович \\ кандидат экономических наук, ведущий научный сотрудник \\ Института мировой экономики и международных финансов \\ Финансовый университет при Правительстве Российской Федерации, Россия, Москва \\ E-mail: palekseev@fa.ru
}

Одной из актуальных проблем развития Евразийского экономического союза (далее также ЕАЭС, Союз) является расширение использования национальных валют его государств-членов в международных расчётах. В статье отмечена тенденция увеличения доли национальных валют стран ЕАЭС во взаимной торговле, начиная с 2013 года, однако сохраняется значительный потенциал её дальнейшего роста. Проанализированы сдерживающие факторы расширения сферы использования денежных единиц в расчетах между государствами-членами ЕАЭС. Обоснован комплексный подход к решению проблемы повышения роли национальных валют стран ЕАЭС в международных расчётах, сочетающий планомерное развитие экономики, запуск механизмов эффективной интеграции, базирующейся на рыночных принципах, улучшение инвестиционного климата и реализацию масштабных совместных проектов. В статье разработаны направления активизации роли национальных валют стран ЕАЭС в международных расчётах.

Ключевые слова: Евразийский экономический союз, национальные валюты, международные расчёты, международная промышленная кооперация, Интегрированный валютный рынок ЕАЭС, общее платёжное пространство ЕАЭС.

Задача расширения использования национальных валют стран ЕАЭС в международных расчётах закреплена в ст. 64 Договора о ЕАЭС и Приложении № 15 «Протокол о мерах, направленных на проведение согласованной валютной политики» к Договору о ЕАЭС [1].

Происходящий в настоящее время процесс дедолларизации взаимных расчётов в рамках ЕАЭС объективно обусловлен ослаблением позиций доллара в мировой валютной системе в исторической перспективе. Валюта США потеряла более $95 \%$ своей первичной покупательной способности с момента основания ФРС [2]. По оценкам экономистов, с 1971 г. (после отмены золотого содержания) реальная цена доллара в нефтяном эквиваленте снизилась в 20-30 раз, в золотом эквиваленте - в 40 раз [3].

Во взаимной торговле товарами стран ЕАЭС по итогам последних 7 лет платежи в нацио- нальных валютах увеличились с 63\% в 2013 г. до 74\% в 2019 г. (рисунок 1).

Доля доллара во взаимных расчётах стран ЕАЭС снизилась с 25\% в 2015 г. до 19\% в 2019 г. Доля евро во взаиморасчётах стран Союза составляла за рассматриваемый период 5-7\%. Доля других национальных валют, прежде всего казахстанского тенге, в среднем составляет около $2 \%$ (таблица 1 ).

Во взаимной торговле товарами стран ЕАЭС с Россией доминирует российский рубль (таблица 2).

Вместе с тем, в расчетах по взаимной торговле государств-членов ЕАЭС без участия России наибольший удельный вес занимает доллар США (таблица 3).

В торговле стран ЕАЭС с третьими странами доля национальных валют в обслуживании платежей за импорт составляет в среднем около

\footnotetext{
* Статья подготовлена по результатам исследований, выполненных за счет бюджетных средств по государственному заданию Финуниверситету.
} 


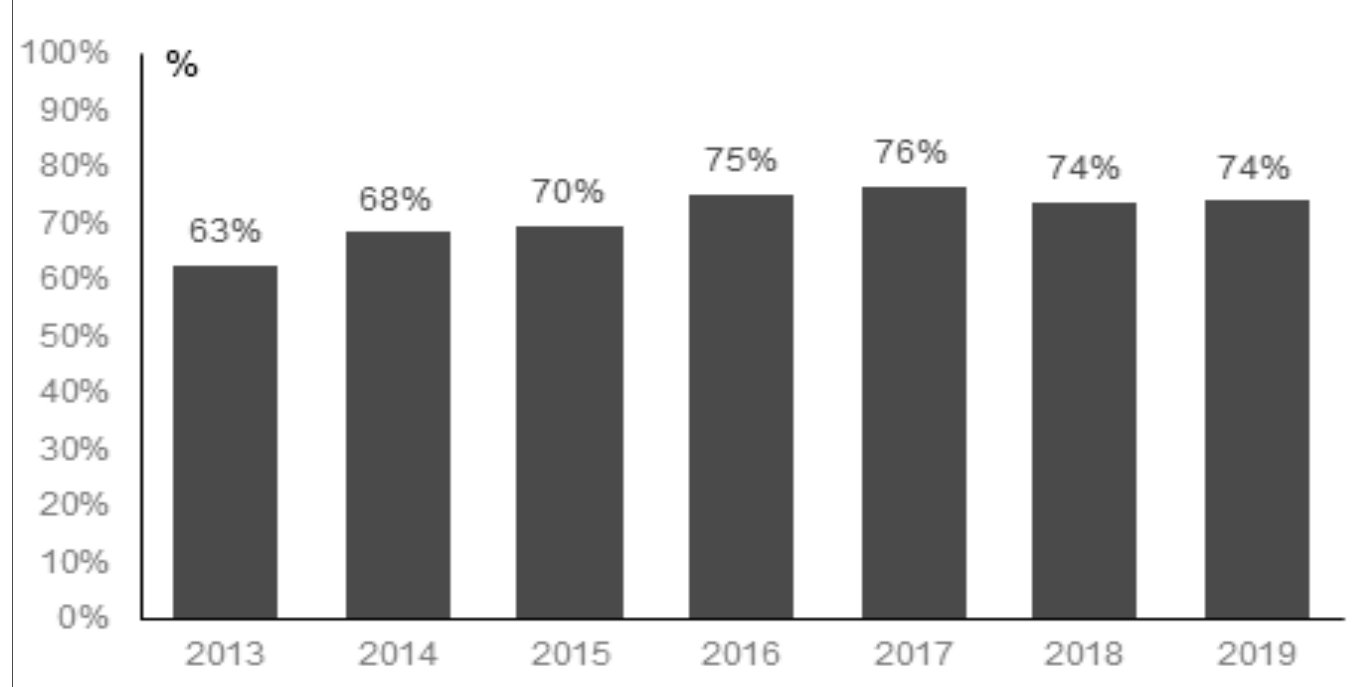

Рисунок 1. Доля национальных валют во взаимной торговле товарами стран ЕАЭС в 2013-2019 гг., \% Источник: доклад «Повышение роли национальных валют ЕАЭС в международных расчётах». М.: ЕАБР, 2021 г. С. 9. URL: http://eabr.org/analytics/special-reports. Дата обращения: 2.08.2021.

Таблиц̧ 1. Валютная структура взаимного товарооборота государств-членов ЕАЭС в 2015-2019 гг., \%

\begin{tabular}{|l|c|c|c|c|c|}
\hline \multicolumn{1}{|c|}{ Валюты } & 2015 & 2016 & 2017 & 2018 & 2019 \\
\hline Российский рубль & 68 & 74 & 75 & 73 & 72 \\
\hline Доллар США & 25 & 19 & 18 & 19 & 19 \\
\hline Евро & 5 & 5 & 5 & 7 & 7 \\
\hline Прочие валюты стран ЕАЭС & 2 & 1 & 2 & 1 & 2 \\
\hline
\end{tabular}

Источник: доклад «Повышение роли национальных валют ЕАЭС в международных расчетах». М.: ЕАБР, 2021 г. С. 9. URL: http://eabr.org/analytics/special-reports. Дата обращения: 2.08.2021.

Таблица 2. Валютная структура торговли товарами отдельных стран ЕАЭС с Россией в 2019 г., \%

\begin{tabular}{|l|c|c|c|c|}
\hline \multicolumn{1}{|c|}{ Страны } & Рубли & Доллары & Евро & Прочие \\
\hline Кыргызстан & 58 & 40 & 2 & 0 \\
\hline Казахстан & 63 & 28 & 4 & 5 \\
\hline Беларусь & 82 & 9 & 8 & 1 \\
\hline
\end{tabular}

Источник: доклад «Повышение роли национальных валют ЕАЭС в международных расчетах». М.: ЕАБР, 2021 г. С. 10. URL: http://eabr.org/analytics/special-reports. Дата обращения: 2.08.2021.

Таблица 3. Валютная структура расчетов по взаимной торговли товарами отдельных стран ЕАЭС без участия России в 2019 г., \%

\begin{tabular}{|l|c|c|c|c|}
\hline \multicolumn{1}{|c|}{ Страны } & Рубли & Доллары & Евро & Прочие \\
\hline Кыргызстан & 4 & 76 & 2 & 18 \\
\hline Казахстан & 6 & 82 & 11 & 1 \\
\hline Беларусь & 29 & 58 & 13 & 0 \\
\hline
\end{tabular}

Источник: доклад «Повышение роли национальных валют ЕАЭС в международных расчетах». М.: ЕАБР, 2021 г. С. 10. URL: http://eabr.org/analytics/special-reports. Дата обращения: 2.08.2021. 
24\%. В обслуживании экспорта их доля значительно ниже - по итогам 2019 г. она составила 9\% (рисунок 2).

Вышеприведенные данные свидетельствуют о значительном потенциале расширения использования национальных валют государствчленов ЕАЭС в международных расчётах. Реализация данного потенциала в настоящее время сдерживается следующими факторами:
- недостаточный уровень структурной диверсификации экономик и развития финансового сектора экономик стран ЕАЭС по сравнению с развитыми странами;

- низкий уровень взаимной торговли товарами стран ЕАЭС, с тенденцией к его снижению с 59,7 млрд. долл. в 2018 г. до 54,9 млрд. долл. в 2020 г. (таблица 4);

- низкий удельный вес взаимного товаро-

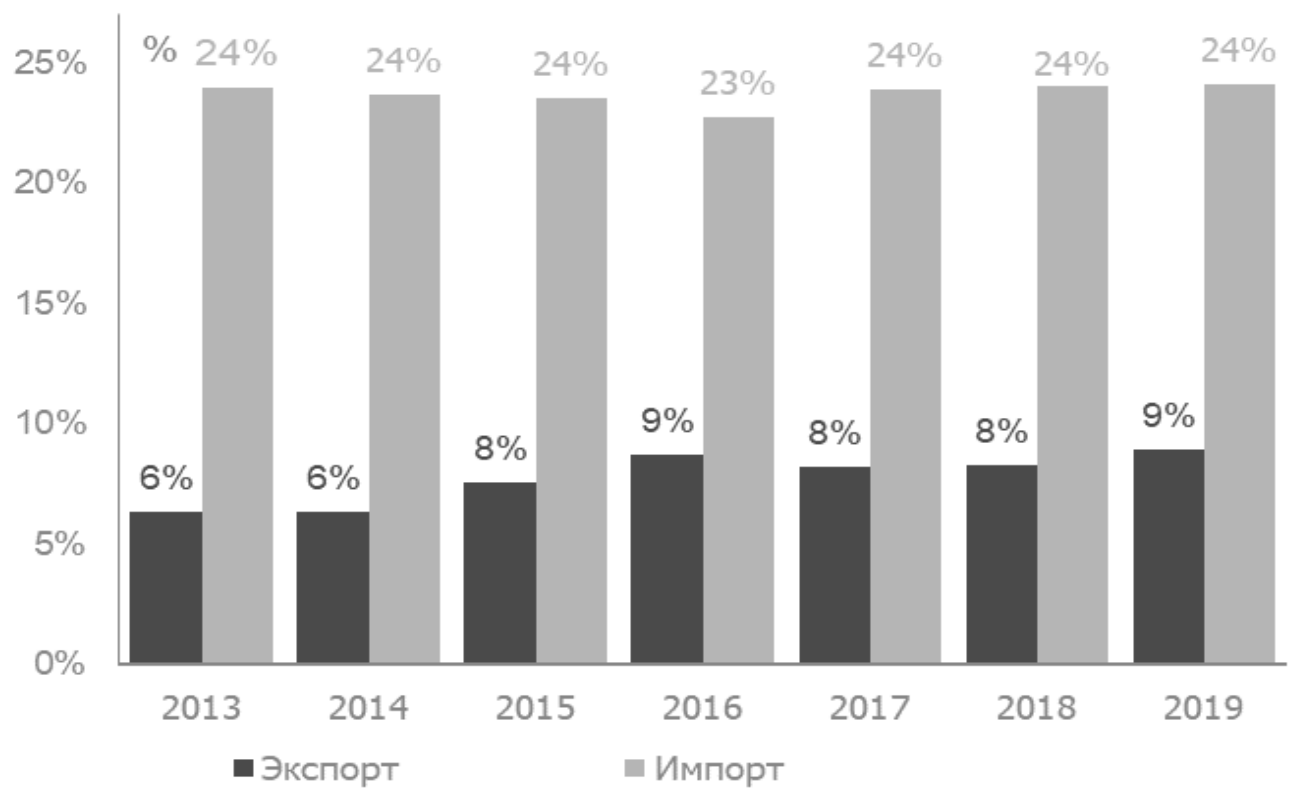

Рисунок 2. Доля национальных валют стран ЕАЭС в их торговле с третьими странами, \% Источник: доклад «Повышение роли национальных валют ЕАЭС в международных расчетах». М.: ЕАБР, 2021 г. C. 8. URL: http://eabr.org/analytics/special-reports. Дата обращения: 2.08.2021.

Таблица 4. Объем взаимной торговли товарами государств-членов ЕАЭС в 2012-2020 гг., млн. долл.

\begin{tabular}{|l|c|c|c|c|c|c|c|c|c|}
\hline $\begin{array}{c}\text { Государства- } \\
\text { участники }\end{array}$ & 2012 & 2013 & 2014 & 2015 & 2016 & 2017 & 2018 & 2019 & 2020 \\
\hline ЕАЭС, всего * & 67856,4 & 64520,0 & 61183,3 & 45605,3 & 42536,4 & 54711,8 & 59721,1 & 61034,1 & 54861,1 \\
\hline Армения & - & - & 324,0 & 256,2 & 392,1 & 571,1 & 689,0 & 760,9 & 705,3 \\
\hline Беларусь & 17116,3 & 17708,4 & 16179,0 & 11007,8 & 11255,1 & 13651,1 & 13891,8 & 14549,0 & 14008,7 \\
\hline Казахстан & 6228,7 & 5933,6 & 7155,0 & 5120,3 & 3917,6 & 5262,5 & 5892,0 & 6317,2 & 5539,0 \\
\hline Кыргызстан & - & - & 637,6 & 399,8 & 417,5 & 541,5 & 568,4 & 621,1 & 546,3 \\
\hline Россия & 44511,4 & 40878,0 & 36887,7 & 28821,2 & 26554,1 & 34685,6 & 38679,9 & 38785,9 & 34061,8 \\
\hline
\end{tabular}

Источник: аналитические обзоры «Об итогах взаимной торговли товарами Евразийского экономического союза» за 20122020 гг. URL: http://www.eurasiancommission.org/ru/act/integr_i_makroec/dep_stat/tradestat/analytics/Documents. Дата обpaщения: 2.08.2021.

* Объем экспортных операций во взаимной торговле товарами. 
оборота в общем объеме их внешней торговли (в среднем 13,5\% на протяжении 2012-2020 гг.*) (таблица 5);

- недостаточный уровень структурной диверсификации взаимной торговли товарами стран ЕАЭС как следствие недостаточного уровня развития промышленной кооперации государств-членов ЕАЭС. На протяжении последнего десятилетия при определенном снижении во взаимном товарообороте доли минеральных товаров удельный вес машин, оборудования и транспортных средств устойчиво стагнирует на уровне около $20 \%$ (таблица 6).

- недостаточные ёмкость и ликвидность валютных рынков стран ЕАЭС, отсутствие глубокой биржевой ликвидности по прямым котировкам пар их национальных валют, затрудняющие взаимные валютообменные операции;

- высокая волатильность курсов валют стран ЕАЭС (таблица 7).

Как следует из таблицы 7, в 2015-2020 гг. курсы четырёх валют стран ЕАЭС (кроме армян- ского драма) к доллару США были более волатильны, чем курс евро к американской валюте. Сравнение коэффициентов вариации обменных курсов стран ЕАЭС свидетельствует, что наиболее волатильной валютой среди стран ЕАЭС является белорусский рубль, далее следуют российский рубль, казахстанский тенге, киргизский сом и армянский драм.

- сохранение препятствий на внутреннем рынке факторов производства ЕАЭС (их количество на 1 августа 2021 г. составило 56) [4]);

- неразвитость рынка финансовых инструментов, номинированных в национальных валютах стран ЕАЭС;

По результатам опроса представителей бизнеса, национальных и наднациональных регуляторов и экспертного сообщества, проведенного Евразийским банком развития в 2017 г., к основным препятствиям для роста доли национальных валют в обороте относятся: высокие валютные риски (68,3\% ответов участников опроса), сложившиеся неадекватные современным

* В практике других региональных объединений взаимная торговля достигает значительно более высоких показателей, например, в ЕС-65\%, в НАФТА-40\%, в АСЕАН-25\%. По мнению авторов, для обеспечения долгосрочной устойчивости интеграционного объединения доля взаимной торговли в общем объеме внешней торговли должна составлять не менее $25 \%$.

Таблица 5. Доля взаимной торговли стран ЕАЭС в общем объеме их внешней торговли в 2012-2020 гг., \%

\begin{tabular}{|l|c|c|c|c|c|c|c|c|c|}
\hline & 2012 & 2013 & 2014 & 2015 & 2016 & 2017 & 2018 & 2019 & 2020 \\
\hline Доля, \% & 12,1 & 12,1 & 12,3 & 13,6 & 14,4 & 14,6 & 13,5 & 14,4 & 14,8 \\
\hline
\end{tabular}

Источник: аналитические обзоры «Об итогах взаимной торговли товарами Евразийского экономического союза» за 20122020 гг. URL: http://www.eurasiancommission.org/ru/act/integr i makroec/dep stat/tradestat/analytics/Documents. Дата обращения: 2.08.2021.

Таблица 6. Структура совокупного экспорта во взаимной торговле стран ЕАЭС в 2012-2020 гг. по укрупненным товарным группам, \%

\begin{tabular}{|l|c|c|c|c|c|c|c|c|c|}
\hline \multicolumn{1}{|c|}{ Товарные группы } & 2012 & 2013 & 2014 & 2015 & 2016 & 2017 & 2018 & 2019 & 2020 \\
\hline Минеральные продукты & 37,4 & 33,0 & 30,7 & 33,4 & 27,0 & 27,5 & 28,7 & 25,8 & 21,6 \\
\hline $\begin{array}{l}\text { Машины, оборудование и транс- } \\
\text { портные средства }\end{array}$ & 21,0 & 20,4 & 21,5 & 16,4 & 17,9 & 18,6 & 19,1 & 19,8 & 20,0 \\
\hline $\begin{array}{l}\text { Продовольственные товары и сель- } \\
\text { скохозяйственное сырье }\end{array}$ & 10,2 & 12,8 & 13,9 & 15,2 & 16,6 & 15,2 & 14,6 & 15,6 & 17,9 \\
\hline Металлы и изделия из них & 12,7 & 12,9 & 11,3 & 10,6 & 11,3 & 13,2 & 13,2 & 12,7 & 12,3 \\
\hline $\begin{array}{l}\text { Продукция химической промыш- } \\
\text { ленности }\end{array}$ & 9,0 & 10,0 & 10,2 & 10,5 & 12,4 & 12,1 & 11,6 & 12,1 & 13,1 \\
\hline Другие товары & 10,3 & 10,9 & 12,4 & 13,9 & 14,8 & 13,4 & 12,8 & 14,0 & 15,1 \\
\hline Экспорт - всего & 100,0 & 100,0 & 100,0 & 100,0 & 100,0 & 100,0 & 100,0 & 100,0 & 100,0 \\
\hline
\end{tabular}

Источник: Аналитические обзоры «Об итогах взаимной торговли товарами Евразийского экономического союза» за 20122020 гг. URL: http://www.eurasiancommission.org/ru/act/integr i makroec/dep stat/tradestat/analytics/Documents. Дата oбpaщения: 2.08.2021. 
Таблица 7. Официальные курсы валют стран ЕАЭС и евро в 2015-2020 гг., на конец года, единиц за 1 долл., и коэффициенты их вариации, \%

\begin{tabular}{|l|c|c|c|c|c|c|c|}
\hline \multicolumn{1}{|c|}{ Валюты } & 2015 & 2016 & 2017 & 2018 & 2019 & 2020 & $\begin{array}{c}\text { Коэффици- } \\
\text { ент вариа- } \\
\text { ции",\% }\end{array}$ \\
\hline Армянский драм & 483,75 & 483,94 & 484,10 & 483,75 & 479,70 & 522,91 & 3,34 \\
\hline Белорусский рубль & 1,86 & 1,96 & 1,97 & 2,16 & 2,10 & 2,57 & 12,00 \\
\hline Казахстанский тенге & 339,47 & 333,28 & 331,31 & 380,44 & 381,18 & 420,91 & 9,83 \\
\hline Киргизский сом & 75,90 & 69,23 & 68,84 & 69,85 & 69,64 & 82,74 & 7,67 \\
\hline Российский рубль & 72,88 & 60,66 & 57,60 & 69,47 & 61,91 & 73,87 & 10,42 \\
\hline \multicolumn{7}{|c|}{ Справочно } \\
\hline Евро & 0,92 & 0,96 & 0,83 & 0,87 & 0,89 & 0,81 & 5,98 \\
\hline
\end{tabular}

Источник: Финансовая статистика Евразийского экономического союза. Статистический сборник. М.: ЕЭК, 2020. С. 50. URL: http://eurasiancommission.org; официальные сайты центральных (национальных) банков государств-членов ЕАЭС; URL: https://www.ecb.europa.eu/stats/policy and exchange rates/euro reference exchange rates. Дата обращения: 2.08.2021.

* Коэффициент вариации валютного курса рассчитывается как процентное отношение его стандартного отклонения к его среднему значению за период и характеризует степень волатильности валютного курса.

требованиям бизнес-практики (51\% ответов участников опроса), отсутствие экономических стимулов (44,5\% ответов участников опроса) [5].

Важная роль в процессе расширения использования национальных валют принадлежит Интегрированному валютному рынку (ИВР) ЕАЭС, созданному на основе Соглашения о сотрудничестве в области организации ИВР, подписанного главами государств-членов Евразийского экономического сообщества 25.01.2006 г. [6]. В данном Соглашении дано определение ИВР и сформулированы его основные принципы. Эти положения были позже включены в Договор о ЕАЭС. Согласно п. 2 Протокола о мерах, направленных на проведение согласованной валютной политики (Приложение № 15 к Договору о ЕАЭС), ИВР - это совокупность внутренних валютных рынков государств-членов, объединенных общими принципами функционирования и государственного регулирования [1]. Наибольшее количество участников ИВР ЕАЭС в настоящее время зарегистрировано на Московской бирже. В их числе коммерческие банки Беларуси, Казахстана, Кыргызстана и Таджикистана, На- циональный банк Республики Беларусь, Национальный банк Таджикистана, а также Межгосударственный банк и Евразийский банк развития [7].

В настоящее время основным препятствием для развития ИВР ЕАЭС являются небольшие (по сравнению с развитыми странами) ёмкость и ликвидность валютных рынков государствчленов ЕАЭС (таблица 8), отсутствие глубокой биржевой ликвидности по прямым парам их национальных валют, что во многом обусловлено недостаточными уровнями структурной диверсификации экономик и развития финансовых секторов стран Союза [7].

В целях углубления и повышения ликвидности ИВР ЕАЭС, обеспечения глубокой биржевой ликвидности по прямым валютным парам необходимо активизировать развитие института маркет-мейкеров по национальным валютам на биржах стран ЕАЭС. Этому может способствовать принятие следующих мер:

1. Разработка и согласование базовых элементов и индикаторов работы маркет-мейкеров на валютных рынках ЕАЭС, включающих: цели,

Таблица 8. Динамика валютных торгов стран ЕАЭС в 2013-2019 гг., млрд. долл.

\begin{tabular}{|l|c|c|c|c|c|c|c|}
\hline \multicolumn{1}{|c|}{ Страны } & 2013 & 2014 & 2015 & 2016 & 2017 & 2018 & 2019 \\
\hline Беларусь & 32,0 & 30,0 & 17,0 & 9,0 & 9,0 & 8,0 & 8,0 \\
\hline Казахстан & 121,0 & 188,0 & 299,0 & 106,0 & 228,0 & 137,0 & 105,0 \\
\hline Россия (х100) & 49,0 & 60,0 & 51,0 & 49,0 & 60,0 & 56,0 & 48,0 \\
\hline Армения & 0,7 & 0,7 & 0,3 & 2,0 & 2,0 & 2,0 & 2,0 \\
\hline Кыргызстан & 1,2 & 1,9 & 1,8 & 1,2 & 0,8 & 1,3 & 0,9 \\
\hline ЕАЭС & 203,9 & 280,6 & 369,1 & 167,2 & 299,8 & 204,3 & 163,9 \\
\hline
\end{tabular}

Источник: Финансовая статистика Евразийского экономического союза. Статистический сборник. М.: ЕЭК, 2020. С. 90. URL: http://eurasiancommission.org. Дата обращения: 2.08.2021. 
задачи, основные принципы, показатели качества работы и экономической эффективности.

2. Формирование потенциального списка маркет-мейкеров по каждой национальной валюте (с учетом пожеланий участников рынка и национальных регуляторов).

3. Формирование пула маркет-мейкеров из участников ИВР по каждой национальной валюте.

Мировой опыт интернационализации национальных валют свидетельствует о необходимости активной государственной экономической политики в этой сфере. Так, в Китае политика интернационализации юаня не ограничивалась исключительно реализацией технических условий развития китайского валютного рынка, она сопровождалась устойчивым социальноэкономическим развитием страны за счёт проведения активной государственной экономической политики [5].

По мнению экспертов Евразийского банка развития, для эффективного расширения использования национальных валют в международных расчётах необходим комплексный подход, сочетающий планомерное развитие экономики, запуск механизмов эффективной интеграции, базирующейся на рыночных принципах, улучшение инвестиционного климата и реализацию масштабных совместных проектов [5].

Важная роль в расширении использования национальных валют стран ЕАЭС в их международных расчётах принадлежит развитию общего платёжного пространства (ОПП) ЕАЭС, которое предусмотрено Стратегическими направлениями развития евразийской экономической интеграции на период до 2025 года, утвержденными Решением Высшего Евразийского экономического совета от 11 декабря 2020 г. № 12 [8] и Концепцией формирования общего финансового рынка Евразийского экономического союза, утвержденной Решением Высшего Евразийского экономического совета от 1 октября 2019 г. № 20 [9].

Необходимым условием успешного развития ОПП ЕАЭС, стабильного и эффективного функционирования национальных платёжных систем (НПС) стран Союза является их соответствие международным стандартам, прежде всего «Основополагающим принципам для системно значимых платёжных систем» [10], разработанным Комитетом по платежам и рыночным ин- фраструктурам (КПРИ) Банка международных расчётов, «Принципам для инфраструктур финансового рынка» (ПИФР) [11], разработанным КПРИ совместно с Техническим комитетом Международной организации комиссий по ценным бумагам, а также «Руководству по киберустойчивости для инфраструктур финансового рынка» [12], разработанному КПРИ совместно с Международной организацией комиссий по ценным бумагам.

В Российской Федерации, как и в других государствах-членах ЕАЭС, правовое регулирование НПС осуществляется с учетом международных стандартов. Так, статьями 22,23,24 Закона РФ от 29.06.2011 г. № 161-ФЗ «О национальной платёжной системе» предусмотрено выявление системно и социально значимых платёжных систем и следование стандартам наилучшей международной практики, подлежащее оценке со стороны Банка России в рамках функции наблюдения в НПС [13]. В качестве такого документа Банком России приняты стандарты ПИФР, применяемые в отношении системно и социально значимых платёжных систем [14].

Аналогичные изменения произошли и в других странах ЕАЭС, однако вопрос о соотношении и соответствии количественных и качественных критериев их значимости требует рассмотрения. Как считает П.А. Тамаров, в целом он связан с характеристиками субъектного состава НПС в различных странах и их гармонизацией в целях единообразного подхода ЦНБ к осуществлению контрольных функций в НПС (платёжного оверсайта). В этой связи необходима гармонизация национальных законодательств стран Союза в сфере платёжных систем на основе международных стандартов в данной области [14].

Одной из особенностей взаимной торговли товарами стран ЕАЭС является значительная доля минеральных продуктов в её структуре (21,6\% в 2020 г. [15]). В связи с этим назрела потребность в создании благоприятных институциональных и инфраструктурных условий для включения в долгосрочные договоры на поставку энергоносителей и других сырьевых товаров положений о номинировании валюты цены и валюты платежа в национальных валютах стран ЕАЭС.

Исходя из вышеизложенного, для повышения доли национальных валют стран ЕАЭС в международных расчётах необходимо акцентировать внимание на следующих направлениях: 
1. Принятие мер по развитию международной промышленной кооперации и взаимной торговли государств-членов ЕАЭС (восстановление Единого таможенного тарифа ЕАЭС, устранение препятствий на внутреннем рынке ЕАЭС, формирование единого цифрового пространства промышленного производства, кооперации и торговли в Союзе)*.

2. Создание необходимых институциональных и инфраструктурных условий для включения в долгосрочные договоры на поставку энергоносителей и других сырьевых товаров положений о номинировании валюты цены и валюты платежа в национальных валютах стран ЕАЭС.

3. Создание необходимых институциональных и инфраструктурных условий для включения в межгосударственные соглашения положений о частичном осуществлении платежей в пользующихся спросом национальных валютах (в первую очередь, в российских рублях).

4. Привлечение новых стран (стран БРИКС, Вьетнама, Турции, Ирана и других) к участию в ИВР ЕАЭС в целях расширения расчётов с ними в национальных валютах стран ЕАЭС.

5. Формирование и развитие института маркет-мейкеров на биржах стран ЕАЭС по национальным валютам, для чего необходимы: a) разработка и согласование базовых элементов и индикаторов работы маркет-мейкеров на валютных рынках ЕАЭС, включающих: цели, задачи, основные принципы, показатели качества работы и экономической эффективности; б) формирование потенциального списка маркет-мейкеров по каждой национальной валюте (с учетом пожеланий участников рынка и национальных регуляторов); в) формирование пула маркет-мейкеров из участников ИВР по каждой национальной валюте.

6. Гармонизация национальных законодательств стран ЕАЭС в сфере платёжных систем на основе международных стандартов в данной области.

7. Распространение налогового режима национальных государственных ценных бумаг стран ЕАЭС на государственные ценные бумаги остальных государств-членов Союза в целях расширения использования их национальных валют во взаимных инвестициях.

8. Разработка плана мероприятий («дорожной карты») по реализации Концепции формирования общего финансового рынка ЕАЭС в целях создания нормативной правовой базы ЕАЭС в финансовой сфере.

Реализация вышеприведенных мер окажет содействие расширению использования национальных валют государств-членов ЕАЭС в международных расчётах, успешному развитию евразийской экономической интеграции.

\section{Библиографический список}

1. Договор о Евразийском экономическом союзе от 29 мая 2014 г. (с изменениями и дополнениями) // СПС «Гарант». Дата обращения: 2.08.2021.

2. Рикардс Д. Валютные войны. М.: Эксмо, 2015. 368 с.

3. Звонова Е.А., Кузнецов А. В., Пищик В.Я., Сильвестров С. Н. Особенности и перспективы построения двухконтурной валютно-финансовой системы на национальном и региональном уровне // Мир новой экономики. 2020. № 1 .

4. Реестр препятствий на внутреннем рынке ЕАЭС. URL: https://barriers.eaeunion.org/ru-ru/Pages/obstacles. aspx. Дата обращения: 2.08.2021.

5. Доклад «Повышение роли национальных валют ЕАЭС в международных расчётах». M.: EAБP, 2021 г. URL: http://eabr.org/analytics/special-reports. Дата обращения: 2.08.2021.

6. Соглашение о сотрудничестве в области организации интегрированного валютного рынка государствчленов Евразийского экономического сообщества от 25 января 2006 г. URL: http://docs.cntd.ru/ document/902042716. Дата обращения: 2.08.2021.

7. Мишина В.Ю., Хомякова Л.И. Приоритеты интеграции финансовых рынков и дедолларизации на евразийском пространстве в свете Концепции формирования общего финансового рынка ЕАЭС // Научные труды ИНП РАН. 2020. № 18.

\footnotetext{
* Более подробно данные меры описаны в статье: Алексеев П. В. Развитие международной производственной кооперации в ЕАЭС // Международная экономика. 2020. № 9. С. 43-53.
} 
8. Стратегические направления развития евразийской экономической интеграции на период до 2025 года (утверждены Решением Высшего Евразийского экономического совета от 11 декабря 2020 г. № 12). URL: http://www.eurasiancommission.org. Дата обращения: 2.08.2021.

9. Концепция формирования общего финансового рынка Евразийского экономического союза (утверждена Решением Высшего Евразийского экономического совета от 1 октября 2019 г. № 20). URL: http://www. eurasiancommission.org. Дата обращения: 2.08.2021.

10. Core Principles for Systematically Important Payment Systems. BIS, Committee on Payment and Settlement Systems, January 2001. https://www.bis.org/cpmi/publ/d43.pdf. Дата обращения: 2.08.2021.

11. Principles for financial market infrastructures. BIS, Committee on Payment and Settlement Systems; Technical Committee of the International Organization of Securities Commissions, April 2012. URL: https:/www.bis.org/ cpmi/publ/d101a.pdf. Дата обращения: 2.08.2021.

12. Guidance on cyber resilience for financial market infrastructures. BIS, Committee on Payment and Settlement Systems, Board of the International Organization of Securities Commissions, June 2016. URL: https://www.bis. org/cpmi/publ/d146.pdf. Дата обращения: 2.08.2021.

13. Закон РФ от 27.06.2011 г. № 161 «О национальной платёжной системе» (с изменениями и дополнениями). URL: http://pravo.gov.ru/proxy/ips/?docbody=\&nd=102148779. Дата обращения: 2.08.2021.

14. Тамаров П.А. Перспективы платёжной системы ЕАЭС // Большая Евразия: развитие, безопасность, сотрудничество. Ежегодник. Вып. 3. Ч. 1.- М.: ИНИОН РАН, 2020.

15. Аналитический обзор «Об итогах взаимной торговли товарами Евразийского экономического союза в 2020 Г». URL: http://www.eurasiancommission.org/ru/act/integr i makroec/dep stat/tradestat/analytics/Documents. Дата обращения: 2.08.2021. 